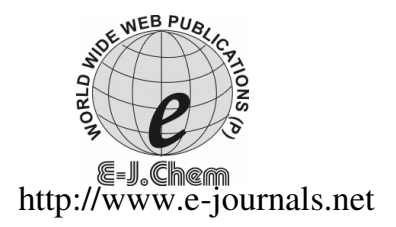

ISSN: 0973-4945; CODEN ECJHAO

E-Journal of Chemistry

2011, 8(1), 354-360

\title{
Synthesis of Symmetrical and Asymmetrical Azines Encompassing Naphtho[2,1-b]furan by a Novel Approach
}

\author{
K. VEENA, M. RAMAIAH ${ }^{\S}$, G.K. VANITA, \\ T.S.AVINASH ${ }^{\text {II }}$ and V. P. VAIDYA* \\ Department of Chemistry \\ Maharani's Science College for Women, Bangalore- 560 001, India \\ ${ }^{\S}$ Department of Chemistry \\ NMKRV College for Women, Bangalore- 560011, India \\ ${ }^{\mathbb{D}}$ Department of Studies in Microbiology \\ Mysore University, Mysore-570006, India \\ *Department of Chemistry \\ Kuvempu University, Shankaraghatta- 5777411, India \\ vaidyavijaya@hotmail.com
}

Received 1 June 2010; Accepted 1 August 2010

\begin{abstract}
The starting material 3-nitro-2-acetylnaphtho[2,1-b]furan (2) was obtained by nitration of 2-acetylnaphtho[2,1-b] furan (1), under mild condition. The compound 1 was synthesized by the reaction of 2-hydroxy-1-naphthaldehyde with chloroacetone, where in both condensation and cyclization took place in single step. The reaction of 3-nitro-2-acetylnaphtho[2,1-b]furan (2) with hydrazine hydrate produced corresponding hydrazone (3) in excellent yield, which on treatment with various aromatic aldehydes under different reaction conditions resulted in the formation of symmetrical azines (4a-e) and unsymmetrical azines (5a-e). All the newly synthesized compounds have been characterized by analytical and spectral studies and were screened for antibacterial antibacterial activity against Bacillus subtilus and Alcaligenes fecalies and antifungal activity against Aspergillus nidulans, Aspergillus parasiticus and Aspergillus terrus. The Second Harmonic Generation (SHG) efficiency of some of the synthesized compounds was measured by powder technique using Nd:YAG laser.
\end{abstract}

Keywords: Naphthofurans, Azines, Antibacterial activity, Antifugal activity, NLO

\section{Introduction}

Naphtho[2,1- $b]$ furans are associated with wide spectrum of pharmacological and biological activities. Encouraged by these findings, synthesis of various derivatives of naphtho[2,1-b] furan 
was taken up as a major research project in our laboratory ${ }^{1-4}$. Azines are organic compounds derived from condensation of an aldehyde or a ketone with hydrazine. They can be considered as 2,3-diaza analogues of butadiene. Enormous research work has been carried out on different kinds of azines, both symmetrical and asymmetrical, concerning their application in diverse fields. Azines undergo various types of cyclo addition reactions ${ }^{5,6}$. Azines, both symmetrical and asymmetrical, which are difficult to synthesize, are known to exhibit various activities and find application as Non Linear Optical (NLO) materials. Polyazines are significantly used as non-linear optical (NLO) materials because of their optical transparency ${ }^{7}$. These non-linear optical materials are of particular importance in the development of light based technology for communication and computing ${ }^{8}$.

Introduction of nitro group in organic molecules, some times, enhances the activity of the compounds many folds. The fact that naphtho[2,1-b]furans are associated with wide spectrum of biological and pharmacological activities ${ }^{9-12}$ and importance of azines stimulated our interest to synthesize symmetrical and asymmical azines involving naphtha $[2,1-b]$ furan, especially with nitro substituent on furan ring of naphthofuran moiety.

\section{Experimental}

Melting points were recorded in open capillaries and are uncorrected. The IR spectra were recorded on a FT-IR Research Spectrophotometer Schimadzu $8201 \mathrm{PC}\left(4000-400 \mathrm{~cm}^{-1}\right)$ and NMR on Bruker DRX-300 (300MHz-FT-NMR with low and high temperature facility $-90^{\circ}$ to $\left.+80^{\circ}\right)$. Standard chemical shifts are given in $\delta \mathrm{ppm}$ values. All the reactions were monitored by thin layer chromatographic method. TLC was run on silica gel using ethyl acetate and petroleum ether (10:90) as eluent. The newly synthesized compounds were separated and purified by column chromatography using silica gel (60-120 mesh).

\section{Synthesis of 2-acetylnaphtho[2,1-b] furan (1)}

2-Hydroxy-1-naphthaldehyde(5.16 g, $0.03 \mathrm{~mol})$, chloroacetone $(4.11 \mathrm{~mL}, 0.03 \mathrm{~mol})$ and anhydrous potassium carbonate $(41.5 \mathrm{~g}, 0.03 \mathrm{~mol})$ were heated under reflux temperature for $24 \mathrm{~h}$ in dry acetone $(50 \mathrm{~mL})$. The reaction mixture was filtered and potassium carbonate was washed with acetone. Evaporation of the solvent from the filtrate yielded the product, 2acetylnaphtho[2,1-b] furan $\mathbf{1}$ which was recrystallised from ethanol. Mixed melting point with authentic sample did not show any depression. The IR and ${ }^{1} \mathrm{H}$ NMR spectra of this compound superimposed with known sample.

\section{Synthesis of 3-nitro-2-acetylnaphtho[2,1-b] furan (2)}

A cooled nitrating mixture of concentrated nitric acid and concentrated sulphuric acid in the ratio 1:2 (13 mL : $26 \mathrm{~mL})$ was added very slowly to a cooled solution of 2-acetylnaphtho $[2,1-b]$ furan $(2.24 \mathrm{~g}, 0.01 \mathrm{~mol})$ in glacial acetic acid $(4 \mathrm{~mL})$ and the mixture was stirred for about $30 \mathrm{~min}$ at $5-15^{\circ} \mathrm{C}$. The stirring was continued for $3 \mathrm{~h}$ at the same temperature and the reaction mixture was poured on to crushed ice. The product which was separated as solid was collected, dried recrystallised from aqueous ethanol.

\section{Synthesis of 3-nitro-2-acetylnaphtho[2,1-b]furanhydrazone (3)}

A mixture of 3-nitro-2-acetylnaphtho[2,1-b]furan (2.5 g, $0.01 \mathrm{~mol})$, hydrazine hydrate (1 mL, $0.01 \mathrm{~mol})$, concentrated hydrochloric acid (3-4drops) in ethanol $(30 \mathrm{~mL})$ was heated on a water bath for $6 \mathrm{~h}$. The reaction mixture was poured in to ice water and neutralized with aqueous sodium hydroxide $(5 \%)$ The product that separated as solid was collected by filtration, dried and recrystallised from ethanol. 


\section{Synthesis of Symmetrical azines (4a-e)}

\section{Method A}

A mixture of 3-nitro-2-acetylnaphtho[2,1-b]furanhydrazone $(1.39 \mathrm{~g}, 0.005 \mathrm{~mol})$, benzaldehyde $(0.6 \mathrm{~mL}, 0.005 \mathrm{~mol})$ in ethanol $(60 \mathrm{~mL})$ and concentrated hydrochloric acid (3-4 drops) was refluxed on a water bath for $8 \mathrm{~h}$. The reaction mixture was poured in to ice water and neutralized with aqueous sodium hydroxide (5\%), solid thus separated was collected by filtration and dried. The crude product was a mixture of two compounds, as observed by TLC, having $\mathrm{R}_{\mathrm{f}}$ values 0.85 and 0.2 . These compounds were separated by column chromatography using silica gel 60-120 mesh size. One product was identified as condensed symmetrical azine (4a) and another as the regenerated 3-nitro-2-acetylnaphthofuran which was eluted using ethyl acetate. Similar procedure was adopted to obtain the compounds $\mathbf{4 b - e}$ from $\mathbf{3}$ using substituted benzaldehydes.

\section{Method B}

To a solution of 3-nitro-2-acetylnaphtho[2,1-b]furanhydrazone (1.39 g, $0.005 \mathrm{~mol})$ and benzaldehyde $(1.0 . \mathrm{mL}, 0.01 \mathrm{~mol})$ in ethanol $(60 \mathrm{~mL})$ and concentrated hydrochloric acid (3-4 drops) were added and refluxed on a water bath for $8 \mathrm{~h}$. The reaction mixture was poured in to ice water and neutralized with aqueous sodium hydroxide (5\%). Solid thus separated was collected by filtration and dried. The crude product was a mixture of two compounds, as observed by TLC, having $\mathrm{R}_{\mathrm{f}}$ values 0.85 and 0.2 . One product was identified as condensed symmetrical azine (4a) and another as the regenerated 3-nitro-2 acetylnaphthofuran which was eluted using ethyl acetate. Similar procedure was adopted to obtain the compounds $\mathbf{4 b - e}$ from $\mathbf{3}$ using substituted benzaldehydes.

\section{Synthesis of asymmetrical azines (5 a-e)}

A mixture of 3-nitro-2-acetylnaphtho[2,1-b]furanhydrazone (1.39 g, $0.005 \mathrm{~mol})$ and benzaldehyde $(0.6 \mathrm{~mL}, 0.005 \mathrm{~mol})$ in ethanol $(60 \mathrm{~mL})$ were refluxed on water bath for $6 \mathrm{~h}$, The reaction mixture was poured in to ice water and neutralized with aqueous sodium hydroxide $(5 \%)$, the solid thus separated was collected by filtration and dried. The product was identified as condensed asymmetrical azine (5a). Similar procedure was repeated to get $\mathbf{5 b}$-e from 3 by using appropriate aromatic aldehydes.

\section{Antimicrobial activity}

Antibacterial activity was carried out by using Bacillus subtilus, Alcaligenes fecalies and antifungal activity was carried out using Aspergillus terius, Aspergillus nidulans, Aspergillus parasiticus.

All the bacterial cultures maintained on nutrient agar media (NA), were inoculated into nutrient broth to get $36 \mathrm{~h}$ old bacterial culture and incubated at $35 \pm 2{ }^{\circ} \mathrm{C}$ on a rotary shaker (Labline biotech) at $100 \mathrm{rmp}$. The concentration was adjusted to $1 \times 10^{8} \mathrm{cfu} / \mathrm{mL}$ using UVvisible spectrophotometer (Hitachi U-2000 Japan) by reading the OD of solution to 0.45 $\left(\mathrm{A}_{610 \mathrm{~nm}}\right)^{13}$.

Fungal colonies were cultured on potato dextrose agar (PDA) and incubated at $35^{\circ} \mathrm{C}$ for 5-7 days to induce sporulation. Stock inoculum suspensions were prepared in $2 \mathrm{~mL}$ of sterile distilled water. To obtain spore and mycelium pieces in a sterile tube. After standing for 5 min the thicker particles settle supernatant was placed in another tube shaken in a vortex for $15 \mathrm{~s}$ and the OD of solution adjusted to 0.09 to $0.11\left(\mathrm{~A}_{530 \mathrm{~nm}}\right)$ using spectrophotometer (Hitachi U-2000 Japan) ${ }^{14}$. 


\section{Antimicrobial assay}

The test was performed according to NCCL, (National Committee for Clinical Laboratory Standards ${ }^{15}$ by employing the paper disc diffusion method. The spore suspensions were spread on sterile PDA for fungi and NA plates using the sterile cotton swabs. The sterile paper discs (Whatmann \#1,6mm diameter) were loaded with the known concentration $(2.5 \mathrm{mg}$ extract per disc) of the extract in acetone. The discs were dried and placed on pre-seeded PDA(potato dextrose agar) and nutrient agar plates. The sterile disc loaded with the respective solvents were used as negative control and the discs loaded with nystatin were used as the positive control for fungi and discs loaded with Gentamicin is used as control for bacteria. The plates were incubated at $4{ }^{0} \mathrm{C}$ for 4 hours to ensure complete diffusion and then incubated at $25 \pm 3{ }^{\circ} \mathrm{C}$ for 72 hours. The plates were observed for the inhibition after the incubation and the diameter of the inhibition zones were measured by using the metric scale.

\section{Second harmonic generation measurements}

Nd:YAG laser of fundamental wavelength $1064 \mathrm{~nm}$ was used as the source of light for second harmonic generation (SHG) experiment. The beam from the laser was passed through a couple of high energy laser mirrors (Melles Griot, 99.9\% reflection) and a long pass colored glass filter (RG 645, to reject the light from the flash lamp of laser) before be focused. The energy of the laser beam was kept at $2.60 \mathrm{~mJ} /$ pulse. The incident beam power was measured using a power meter (Scientech Vector H410). The beam was focused into a glass capillary, using a converging lens of $200 \mathrm{~mm}$ focal length. The incoherently scattered $\mathrm{SH}$ photons were collected in the transverse direction using a combination of a monochromator (Triax 550, Jobin Yvon, $0.024 \mathrm{~nm}$ resolution, $1 \mathrm{~mm}$ entrance and exit slit widths) and a photomultiplier tube The second harmonic signal was then sampled, averaged over 512 shots and was recorded in a digital storage oscilloscope

\section{Results and Discussion}

The starting material i.e. 2-acetylnaphtho[2,1-b]furan (1), was synthesized in two steps, the first step involved Reimer-Tiemann reaction of 2-naphthol with chloroform and sodium hydroxide, which resulted in the formation of 2-hydroxy-1-naphthaldehyde and the second step involved conversion of 2-hydroxy-1-naphthaldehyde to 2-acetylnaphtho[2,1-b]furan (1), which was accomplished by treatment of 2-hydroxy-1-naphthaldehyde with chloroacetone, in presence of weak base, potassium carbonate. In the second step condensation and cyclization occurred in single step and the product was obtained in good yield. It underwent smooth nitration with concentrated nitric acid and concentrated sulphuric acid at low temperature using acetic acid as a solvent and produced 3-nitro-2-acetylnaphtho[2,1-b] furan (2). The structure of compound 1 was established by recording its IR and ${ }^{1} \mathrm{H}$ NMR spectra and comparing the same with an authentic sample ${ }^{10}$. The reaction of $\mathbf{2}$ with hydrazine hydrate in ethanol was straight forward and produced corresponding hydrazone $\mathbf{3}$, in excellent yield. The IR spectrum of $\mathbf{3}$ showed strong absorption band at $1623 \mathrm{~cm}^{-1}$ due to carbonyl and broad band at $3446 \mathrm{~cm}^{-1}$ due to $\mathrm{NH}_{2}$ group and at $1527 \mathrm{~cm}^{-1}$ due to $\mathrm{NO}_{2}$ group. The ${ }^{1} \mathrm{H}$ NMR and ${ }^{13} \mathrm{C}$ NMR of this compound confirmed the assigned structure. The hydrazone $\mathbf{3}$ served as an excellent intermediate for the synthesis of symmetrical azines (4a-e) and unsymmetrical azines (5a-e). Thus, very interesting results were obtained when hydrazone (3), was treated with various aromatic aldehydes under different reaction conditions. Different types of compounds were obtained, when the reaction was carried in different ratio of reactants and in presence of hydrochloric acid as catalyst as well as in absence of catalyst. 
Thus, the acid catalyzed reaction of 2-acetyl-3-nitronaphtho[2,1-b]furanhydrazone (3) with benzaldehyde, 4-methoxybenzaldehyde, 3-nitrobenzaldehyde, 4-chlorobenzaldehye and 2-chlorobenzaldehyde in 1:1 mol ratio at reflux temperature in ethanol produced a mixture of two compounds. These compounds were separated by column chromatography and identified as symmetrical azines (4a-e) and 2-acetyl-3- nitronaphtho[2,1-b]furan (2). It has been presumed that, the originally formed mixed azines underwent hydrolysis, under acidic condition and recombined to form symmetrical azines. These were isolated and characterized on the basis of spectral data.

The IR spectrum of $4 \mathbf{a}$ exhibited the absorption band at 1623 due to $\mathrm{C}=\mathrm{N}$. In its ${ }^{1} \mathrm{H}$ NMR spectrum $\left(\mathrm{CDCl}_{3}\right)$ singlet at 8.8 for two $\mathrm{CH}$ protons and multiplet at 7.2-8.3 for aromatic protons were observed. The ${ }^{1} \mathrm{H}$ NMR spectra of compounds $\mathbf{4 b}$-e were consistent with their structures.

Similar reaction was carried out using 3 with respective aldehydes in the molar ratio 1:2 in the presence of an acid. In this case also two products were obtained which were identified as symmetrical azines and regenerated 2-acetyl -3-nitronaphtho [2,1-b]furan.

On the other hand the condensation of 3 with these aldehydes in 1:1 mol ratio in the absence of hydrochloric acid at reflux temperature in ethanol gave a single product. The products thus formed in each case were identified as asymmetrical azines (5a-e) of 2-acetyl3-nitronaphtho[2,1-b]furanhydrozone. The IR spectrum of $\mathbf{5 b}$ exhibited the absorption band at $1605 \mathrm{~cm}^{-1}$ due to $\mathrm{C}=\mathrm{N}$. The ${ }^{1} \mathrm{H}$ NMR spectra of $\mathbf{5 b}$ exhibited a singlet at 3.8 due to $\mathrm{OCH}_{3}$ group and multiplet at 7.0-8.4 for aromatic protons. The characterization data of the synthesized compounds are as shown in Table 1.

Table 1. Analytical data of the synthesized compounds

\begin{tabular}{cccccccc}
\hline Compound & $\mathrm{R}$ & $\begin{array}{c}\mathrm{M} . \mathrm{P} \\
{ }^{\circ} \mathrm{C}\end{array}$ & $\begin{array}{c}\text { Yield } \\
\%\end{array}$ & $\begin{array}{c}\text { Molecular } \\
\text { formula }\end{array}$ & \multicolumn{3}{c}{ Found (calculated) \% } \\
\hline $\mathbf{1}$ & - & 104 & 82 & $\mathrm{C}_{14} \mathrm{H}_{10} \mathrm{O}_{2}$ & $80.1(80.0)$ & $4.71(4.76)$ & - \\
$\mathbf{2}$ & - & 180 & 94 & $\mathrm{C}_{14} \mathrm{H}_{9} \mathrm{NO}_{4}$ & $65.0(65.8)$ & $3.40(3.50)$ & $5.0(5.4)$ \\
$\mathbf{3}$ & - & 155 & 57 & $\mathrm{C}_{14} \mathrm{H}_{11} \mathrm{~N}_{3} \mathrm{O}_{3}$ & $60.0(60.2)$ & $3.50(3.90)$ & $14.9(15.0)$ \\
$\mathbf{4 a}$ & $\mathrm{H}$ & 184 & 60 & $\mathrm{C}_{14} \mathrm{H}_{12} \mathrm{~N}_{2}$ & $79.0(80.7)$ & $5.60(5.76)$ & $13.0(13.4)$ \\
$\mathbf{4 b}$ & $4-\mathrm{OCH}_{3}$ & 178 & 70 & $\mathrm{C}_{16} \mathrm{H}_{16} \mathrm{~N}_{2} \mathrm{O}_{2}$ & $71.0(71.6)$ & $5.01(5.97)$ & $10.0(10.4)$ \\
$\mathbf{4 c}$ & $3-\mathrm{NO}_{2}$ & $>250$ & 62 & $\mathrm{C}_{14} \mathrm{H}_{10} \mathrm{~N}_{4} \mathrm{O}_{2}$ & $63.0(63.1)$ & $3.01(3.75)$ & $20.0(20.2)$ \\
$\mathbf{4 d}$ & $4-\mathrm{Cl}$ & 152 & 72 & $\mathrm{C}_{14} \mathrm{H}_{10} \mathrm{~N}_{2} \mathrm{Cl}_{2}$ & $60.0(60.6)$ & $3.60(3.61)$ & $10.0(10.1)$ \\
$\mathbf{4 e}$ & $2-\mathrm{Cl}$ & 196 & 68 & $\mathrm{C}_{14} \mathrm{H}_{10} \mathrm{~N}_{2} \mathrm{Cl}_{2}$ & $60.0(60.6)$ & $3.60(3.61)$ & $10.0(10.1)$ \\
$\mathbf{5 a}$ & $\mathrm{H}$ & 204 & 70 & $\mathrm{C}_{21} \mathrm{H}_{16} \mathrm{~N}_{3} \mathrm{O}_{3}$ & $70.0(70.3)$ & $4.40(4.46)$ & $11.0(11.7)$ \\
$\mathbf{5 b}$ & $4-\mathrm{OCH}$ & 170 & 80 & $\mathrm{C}_{22} \mathrm{H}_{18} \mathrm{~N}_{3} \mathrm{O}_{4}$ & $67.5(68.0)$ & $4.60(4.63)$ & $10.8(10.8)$ \\
$\mathbf{5 c}$ & $3-\mathrm{NO} \mathrm{O}_{2}$ & 250 & 60 & $\mathrm{C}_{21} \mathrm{H}_{15} \mathrm{~N}_{4} \mathrm{O}_{5}$ & $62.0(62.5)$ & $3.50(3.70)$ & $13.5(13.8)$ \\
$\mathbf{5 d}$ & $4-\mathrm{Cl}$ & 153 & 65 & $\mathrm{C}_{21} \mathrm{H}_{15} \mathrm{~N}_{3} \mathrm{O}_{3} \mathrm{Cl}$ & $64.0(64.1)$ & $3.70(3.80)$ & $10.4(10.6)$ \\
$\mathbf{5 e}$ & $2-\mathrm{Cl}$ & 220 & 64 & $\mathrm{C}_{21} \mathrm{H}_{15} \mathrm{~N}_{3} \mathrm{O}_{3} \mathrm{Cl}$ & $64.0(64.1)$ & $3.70(3.80)$ & $10.4(10.6)$ \\
\hline
\end{tabular}

Antibacterial activity

All the newly synthesized compounds were tested for their antibacterial activity against Bacillus subtilus, Alcaligenes fecalies and antifungal activity against Aspergillus terius, Aspergillus nidulans, Aspergillus parasiticus by paper disc diffusion method. The antibacterial results (Table 2) indicate that among the tested compounds $\mathbf{4 a}$ showed the maximum inhibition $12 \mathrm{~mm}$ inhibition to Bacillus subtilus and $\mathbf{4 d}$ showed $8 \mathrm{~mm}$ inhibition to Bacillus subtilus compared to standard control gentamycin. 


\section{Antifungal activity}

The antifungal screening results indicate that among the tested compounds $\mathbf{4 c}$ showed higher degree of antifungal activity against Aspergillus nidulans i.e. $4 \mathrm{~mm}$ inhibition compared to nystatin which shows $3 \mathrm{~mm}$ inhibition. Compounds $\mathbf{4 a}, \mathbf{5 a}, \mathbf{5 b}$ and $\mathbf{5 c}$ showed almost same degree of activity compared to standard drug.

Table 2. Antimicrobial activity of the synthesized compounds

\begin{tabular}{|c|c|c|c|c|c|}
\hline \multirow{3}{*}{ Compound } & \multicolumn{5}{|c|}{ Zone of inhibition in $\mathrm{mm}$} \\
\hline & \multicolumn{2}{|c|}{ Antibacterial Activity } & \multicolumn{3}{|c|}{ Antifungal Acitivity } \\
\hline & $\begin{array}{l}\text { Bacillus } \\
\text { subtilus }\end{array}$ & $\begin{array}{l}\text { Alcaligenes } \\
\text { fecalies }\end{array}$ & $\begin{array}{l}\text { Aspergillus } \\
\text { nidulans }\end{array}$ & $\begin{array}{l}\text { Aspergillus } \\
\text { parasiticus }\end{array}$ & $\begin{array}{l}\text { Aspergillus } \\
\text { terius }\end{array}$ \\
\hline $4 \mathbf{b}$ & 5 & 2 & - & - & - \\
\hline $5 \mathbf{b}$ & - & - & 2 & - & - \\
\hline $4 d$ & 8 & - & - & - & 2 \\
\hline $5 d$ & - & - & - & - & - \\
\hline $\mathbf{4 a}$ & 12 & - & 3 & - & 3 \\
\hline $5 \mathbf{a}$ & - & - & 3 & - & - \\
\hline $4 c$ & - & - & 4 & - & 4 \\
\hline $5 c$ & - & - & 2 & - & 6 \\
\hline $4 e$ & - & - & - & - & - \\
\hline $5 e$ & - & - & - & - & - \\
\hline Control & 28 & 3 & 3 & 2 & 24 \\
\hline
\end{tabular}

Not active, Control: For antibacterial: Gentamicin (10 $\mu \mathrm{g})$, For antifungal : Nystatin (10 $\mu \mathrm{g}) \mathrm{NLO}$ Studies

The Second harmonic generation (SHG) efficiency of these compounds was measured by powder technique using Nd:YAG laser with Beam Energy $2.51 \mathrm{~mJ} /$ pulse. Among tested compounds, 5d exhibited NLO property with SHG conversion efficiency 2.5 times that of urea and compound $\mathbf{4 a}$ exhibited NLO property with SHG conversion efficiency almost near to potassium dihydrogen phosphate (KDP)

\section{Conclusion}

The present work gives a novel and simple approach for synthesis of symmetrical and asymmetrical azines, which are otherwise difficult to synthesize. Some of the compounds exhibited good antibacterial and antifungal activity. Second harmonic generation efficiency of the tested compounds showed that the compound $\mathbf{5 d}$ has 2.5 times more efficiency that urea. And the compound 4a exhibited NLO property with SHG efficiency almost equal to potassium dihydrogen phosphate.

\section{Acknowledgement}

The authors are thankful to The Principal, NMKRV College Bangalore for providing laboratory facilities and are also thankful to the Head, Sophisticated Instrumentation Facility, IISC, Bangalore, for providing the spectral data. 


\section{References}

1. Vagdevi H M and Vaidya V P, Indian J Heterocyclic Chem., 2001, 10, 253.

2. Vagdevi H M, Latha K P, Vaidya V P, Pai K S R and Vijaya Kumar M L, Indian J Pharm Sci., 2001, 63(4), 286.

3. Mahadevan K M, and Vaidya V P, J Indian Council of Chemist, 2001, 18(2), 78.

4. Mahadevan K M, Vagdevi H M, and Vaidya V P, Indian J Chem., 2003, 42B, 1931-1936.

5. Grashey R and Padwa A, Ed., General Heterocyclic Chemistry Series, John Wiley \& Sons, Newyork, 1984, 733.

6. Wagner-Jauregg T, Synthesis, 1976, 349.

7. Sarojini B K, Narayana B, Ashalatha B V, Indira J and Lobo KG, J Crystal Growth, 2006, 295, 54-59.

8. $\quad$ Nalwa H S, Kakuta A and Mukoh A, J Appl Phys., 1993, 73, 4743.

9. Mahadevan K M, Padmashali B, and Vaidya V P, Indian J Heterocyclic Chem., 2001, 11, 15-20.

10. Kumaraswamy M N and Vaidya V P, Indian J Heterocyclic Chem., 2005, 14, 193.

11. Vaidya.V P, Shreedhara C S, Gopal M, Shabuddin M S and Shenoy P S, Indian J Pharm Sci., 2003, 65(6), 580.

12. Vaidya V P, Vagdevi H M, Mahadevan K M and Shreedhara C S, Indian J Chem., 2004, 43B, 1537.

13. Niranjan Raj S, Shetty N P and Shetty H S, Int J Pest Manage., 2004, 50(1), 41-48.

14. Espinel-Ingroff A, J Clin Microbiol., 2006, 44(10), 3616-3622.

15. National Committee for Clinical Laboratory Standards, Reference method for broth dilution antifungal susceptibility testing filamentous fungi. M-38; Approved standards, Wayne, 2002. 


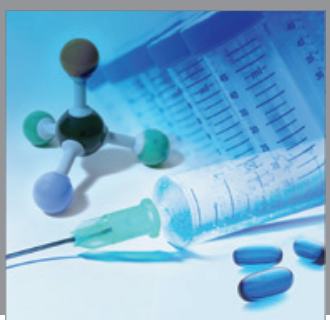

International Journal of

Medicinal Chemistry

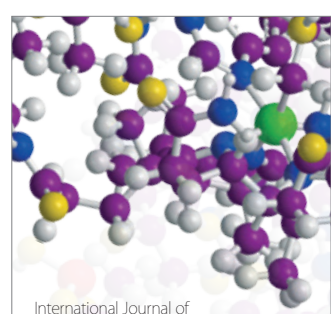

Carbohydrate Chemistry

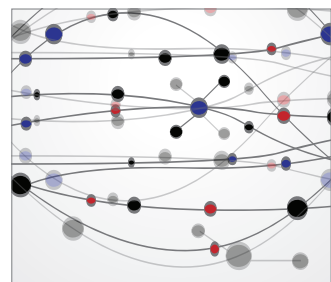

The Scientific World Journal
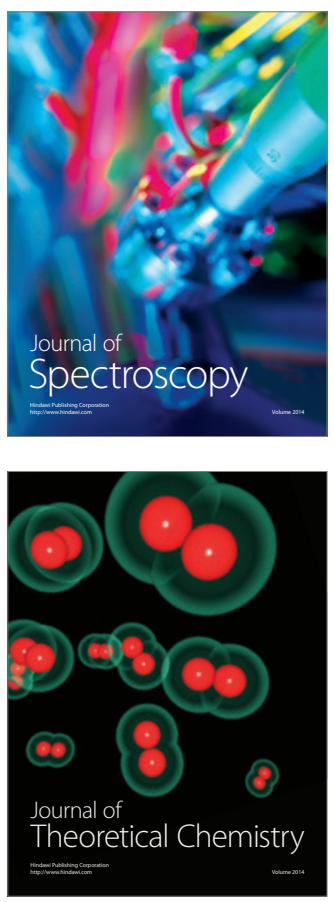
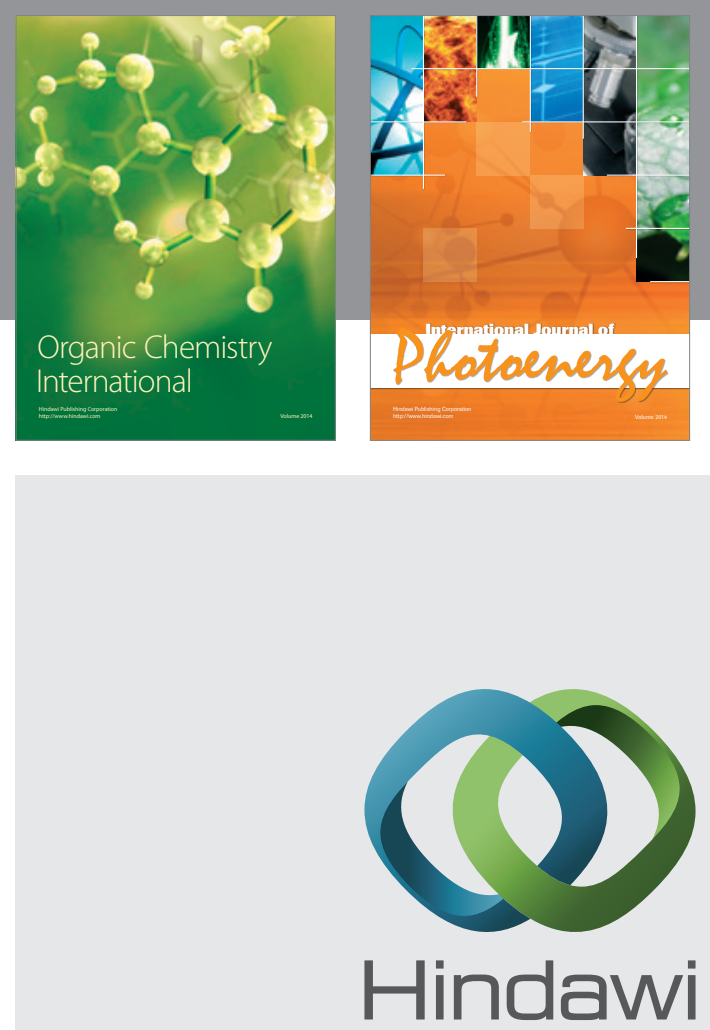

Submit your manuscripts at

http://www.hindawi.com
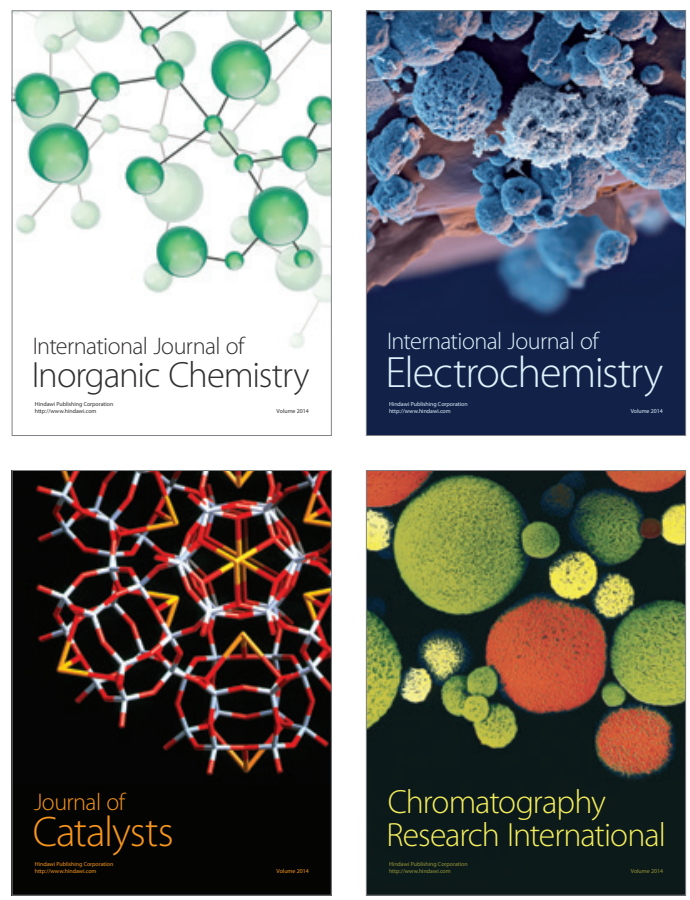
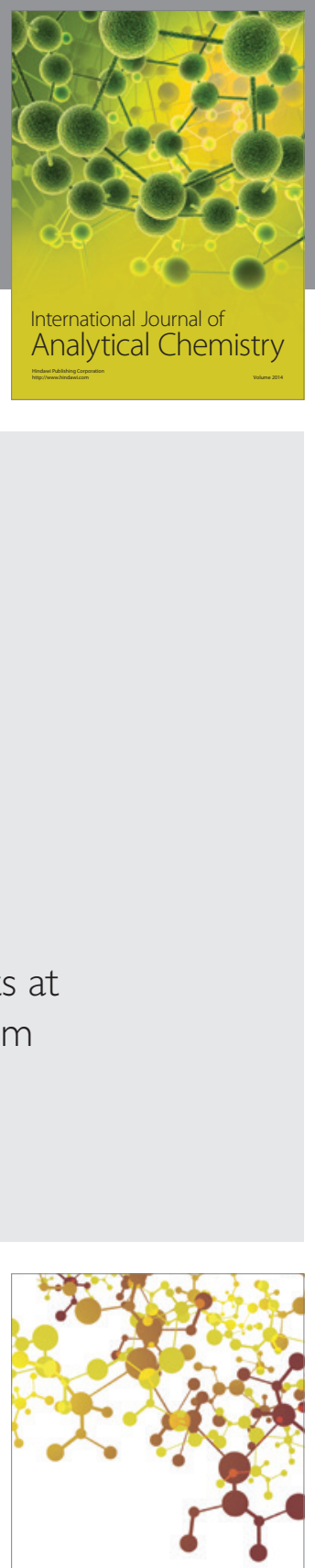

Journal of

Applied Chemistry
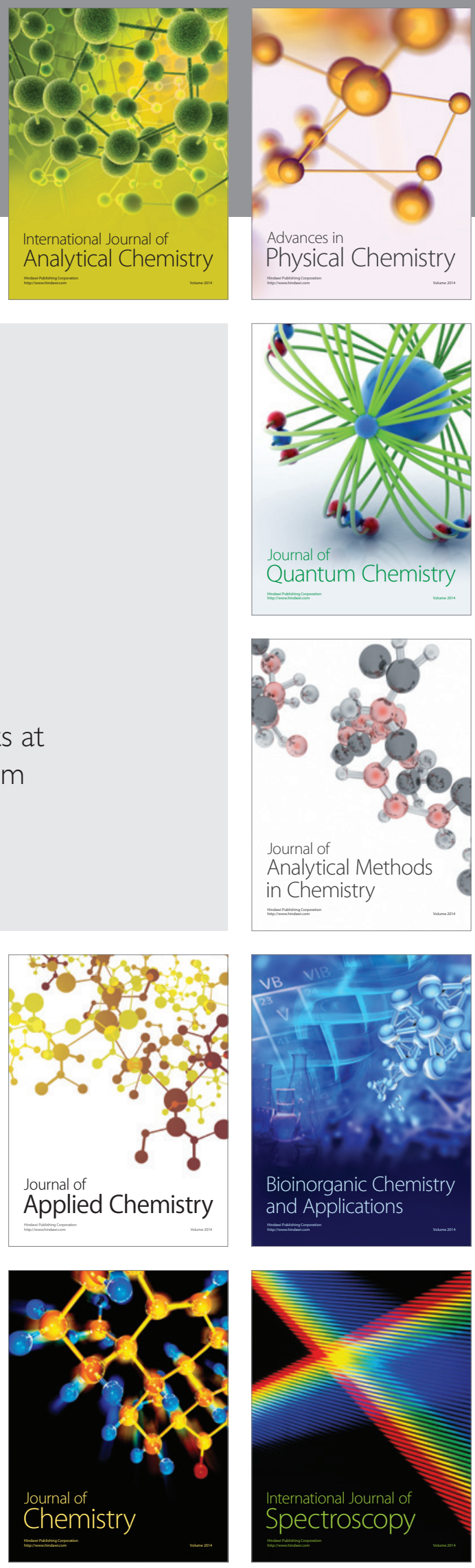